\title{
Gas chromatographic-mass spectrometric analysis of tar compounds formed during pyrolysis of rice husks
}

\author{
V. A. C. HAANAPPEL \\ Biomass Technology Group, University of Twente, P.O. Box 217,7500 AE Enschede (The Netherlands) \\ and \\ T. W. STEVENS, A. HOVESTAD, V. SKOLNIK and R. VISSER* \\ Laboratory for Chemical Analysis, University of Twente, P.O. Box 217, 7500 AE Enschede (The Nether- \\ lands)
}

\begin{abstract}
Pyrolysis of agricultural waste to produce fuel gas involves formation of tars as noxious by-products. In this paper the qualitative analysis of tars formed during pyrolysis of rice husks is presented, based on identification by gas chromatography-mass spectrometry and interpolation of retention times on a polyaromatic hydrocarbon index scale. The influence of some reaction parameters on product formation is briefly discussed.
\end{abstract}

\section{INTRODUCTION}

Biomass can be converted by gasification into a gaseous fuel (producer gas) [1]. The fucl can be used to operate engines, e.g. for the production of electricity. This approach is very useful for third world countries, especially when small production units are used. However, depending on the type of feed and operating conditions, the process can give rise to significant amounts of unpleasant tars. These can contain mutagenic or carcinogenic organic compounds and cause severe pollution of the environment. Reduction of tars can be achieved by adding inorganic additives, or the tars can be catalytically or thermally cracked whilst still in the vapour phase in the raw producer gas.

For the optimization of the process a qualitative and semi-quantitative analysis of the tars is a pre-requisite. It is then possible to examine the amounts formed of different compounds (especially those that are very harmful) under varying conditions.

In the past, formation of tar compounds by gasification of wood has been studied [2,3]; however, there is a tendency to shift to the use of agricultural waste as the feedstock (e.g. in Mali, Ecuador and South East Asia). This paper describes the analysis of compounds formed by pyrolysis of rice husks in laboratory experiments, with the emphasis on the qualitative aspects. 


\section{EXPERIMENTAL}

\section{Pyrolysis}

The experiments described are based on pyrolysis of dried rice husks (normally ca. $6 \mathrm{~g}$ ) in a stream of helium gas at $500^{\circ} \mathrm{C}$ in a Gray-King-type quartz retort. In the first series of experiments husks were used untreated (experiment 1), prepared by dry mixing with $10.7 \%(w / w) \mathrm{K}_{2} \mathrm{CO}_{3}(2), 10.5 \% \mathrm{Na}_{2} \mathrm{Co}_{3}(3), 9.0 \% \mathrm{CaCO}_{3}$ (4) and $1.6 \% \mathrm{KCl}(5)$, and prepared by impregnating with $5.6 \%$ (w/w, dry) $\mathrm{K}_{2} \mathrm{CO}_{3}$ (6), $3.7 \% \mathrm{Na}_{2} \mathrm{CO}_{3}(7), 11.6 \% \mathrm{KCl}(8)$ and $10.5 \% \mathrm{NaCl}$ (9) solutions in water. The gases produced were led into a U-shaped cold-trap $\left(0^{\circ} \mathrm{C}\right)$ provided with glass-wool plugs at both ends.

In the second series the retort was linked with a second reactor; in this reactor an additional flow of helium was used to vary the residence time of the volatiles. The reactor was connected to the cold-trap. Pyrolysis experiments were carried out with an empty reactor at $600^{\circ} \mathrm{C} / 2.4 \mathrm{~s}$ residence time $(10), 700^{\circ} \mathrm{C} / 2.2 \mathrm{~s}(11)$ and $0.6 \mathrm{~s}(12), 900^{\circ} \mathrm{C} / 1.8 \mathrm{~s}(13)$ and $0.5 \mathrm{~s}(14)$, and $100^{\circ} \mathrm{C} / 1.7 \mathrm{~s}(15)$. Finally the reactor was filled with dolomite as a cracking catalyst $\left(600^{\circ} \mathrm{C} / 2 \mathrm{~s}\right.$ residence time) (16).

The tars in the trap were extracted with methanol-acetone, the eluents were evaporated, and the "dry" weight was determined. Tars were dissolved in diethylether and analysed by gas chromatography (GC). A sample resulting from experiment 9 was used for qualitative analysis by gas chromatography-mass spectrometry (GC-MS), and a sample from experiment 14 for a separate qualitative analysis based on polyaromatic hydrocarbon retention times.

\section{Gas chromatography-mass spectrometry}

GC-MS analysis was performed using a Finnigan MAT 90 double-focusing mass spectrometer (electron impact mode) coupled to a Varian 3400 gas chromatograph.

GC conditions were: column, fused-silica SGE (Scientific Glass Engineering, Ringwood, Australia) BP5 (25 m $\times 0.22 \mathrm{~mm} \mathrm{I.D}$; film thickness $0.25 \mu \mathrm{m}$ ); temperature, $1 \mathrm{~min}$ at $40^{\circ} \mathrm{C}$ then $7^{\circ} \mathrm{C} / \mathrm{min}$ to $250^{\circ} \mathrm{C}$ then $1 \mathrm{~min}$ at $250^{\circ} \mathrm{C}$; carrier gas, helium at $1.5 \mathrm{ml} / \mathrm{min}$.

Mass spectrometer parameters were: ionization voltage $70 \mathrm{eV}$; emission current, $1 \mathrm{~mA}$; mass scan, from 40 to 400 dalton; resolution, 1430 (10\% valley definition); sampling frequency, $26500 \mathrm{kHz}$; cycle time, $1.2 \mathrm{~s}$; samples per peak, 8. About 1250 mass spectra were recorded.

GC analysis was performed on a Varian 3400 gas chromatograph. GC conditions were: column, fused-silica SE 54 (J\&W Scientific, Cordova, CA, U.S.A.) (15 $\mathrm{m} \times 0.31 \mathrm{~mm} \mathrm{I.D}$; film thickness $0.25 \mu \mathrm{m}$ ); temperature, $1 \mathrm{~min}$ at $40^{\circ} \mathrm{C}$ then $5^{\circ} / \mathrm{min}$ to $290^{\circ} \mathrm{C}$ then $10 \mathrm{~min}$ at $290^{\circ} \mathrm{C}$; carrier gas, helium at $3 \mathrm{ml} / \mathrm{min}$; injection, on column, $50^{\circ} \mathrm{C}$ at $100^{\circ} \mathrm{C} / \mathrm{min}$ to $300^{\circ} \mathrm{C}$; flame ionization detection at $300^{\circ} \mathrm{C}$, connected to data system Varian Vista CDS 401 .

The mass spectra were identified by an automatic library search (National 
Bureau of Standards Library, 55000 spectra). In those cases where no significant answer was obtained, the spectra were compared with the Eight Peak Index of Mass Spectra [4] or interpreted by the authors.

$\mathrm{GC}$ retention times were converted into retention indices by linear interpolation between retention times of a series of $n$-alkanes [5]. A series of compounds were identified independently by injection of a reference sample. For compounds identified by MS and entered in the Sadtler Retention Index Library [6] the retention indices were compared to the reference values. Polyaromatic hydrocarbons (PAHs) were verified by injection of a series of nine reference PAHs (i.e. phenol, 1-naphthol, 2-naphthol, naphthalene, phenanthrene, anthracene, fluoranthene, pyrene and chrysene) and interpolation of the other PAHs using the $\mathrm{PAH}$ retention index scale [7].

The total weight of material removed from the cold-trap was determined after evaporation of the solvents. The total amount of material (tar) dissolved in diethyl ether was determined by $\mathrm{GC}$, using an average calibration factor to convert peak areas into masses. For two characteristic groups of compounds, viz. the 22 most intense hydroxyaromatics and the 20 most intense PAHs, the sum of the peak areas was calculated and converted into absolute amounts, again using an average calibration factor. The same was done for one of the most suspected compounds, i.e. benz $[a]$ pyrene.

\section{RESULTS AND DISCUSSION}

The reconstructed ion current (RIC) chromatogram of experiment 9 as a function of the mass spectrum number is shown in Fig. 1. The results of the qualitative analysis based on the mass spectra are summarized in Table I. The numbers in the column Sp.No. refer to the mass spectrum numbers. The GC retention times are those obtained from the independent gas chromatogram. This chromatogram is shown in Fig. 2. Since concentrations of higher-boiling compounds were very low, comparison of peaks with retention times above $c a .19$ min was not unambiguous; these times have been left out.

The results of the comparison of the separate run of experiment 14 with the set of PAH reference values are presented in Table II. This table contains almost exclusively PAHs. The chromatogram is given in Fig. 3. (Retention times in Table II are the average of two determinations, which explains the slight differences between Table II and Fig. 3). Compounds identified by independent injection of authentic standards are marked with an asterisk in both tables.

In Table III the total mass of material recovered for each experiment is presented, and the absolute amount of tar dissolved in diethyl ether. In the following two columns the total masses of the 22 most important compounds of Table I (mainly aromatic hydroxyl compounds) and of the 20 most important compounds (almost exclusively PAHs) of Table II are given, and in the last column the mass of benz $[a]$ pyrene. 


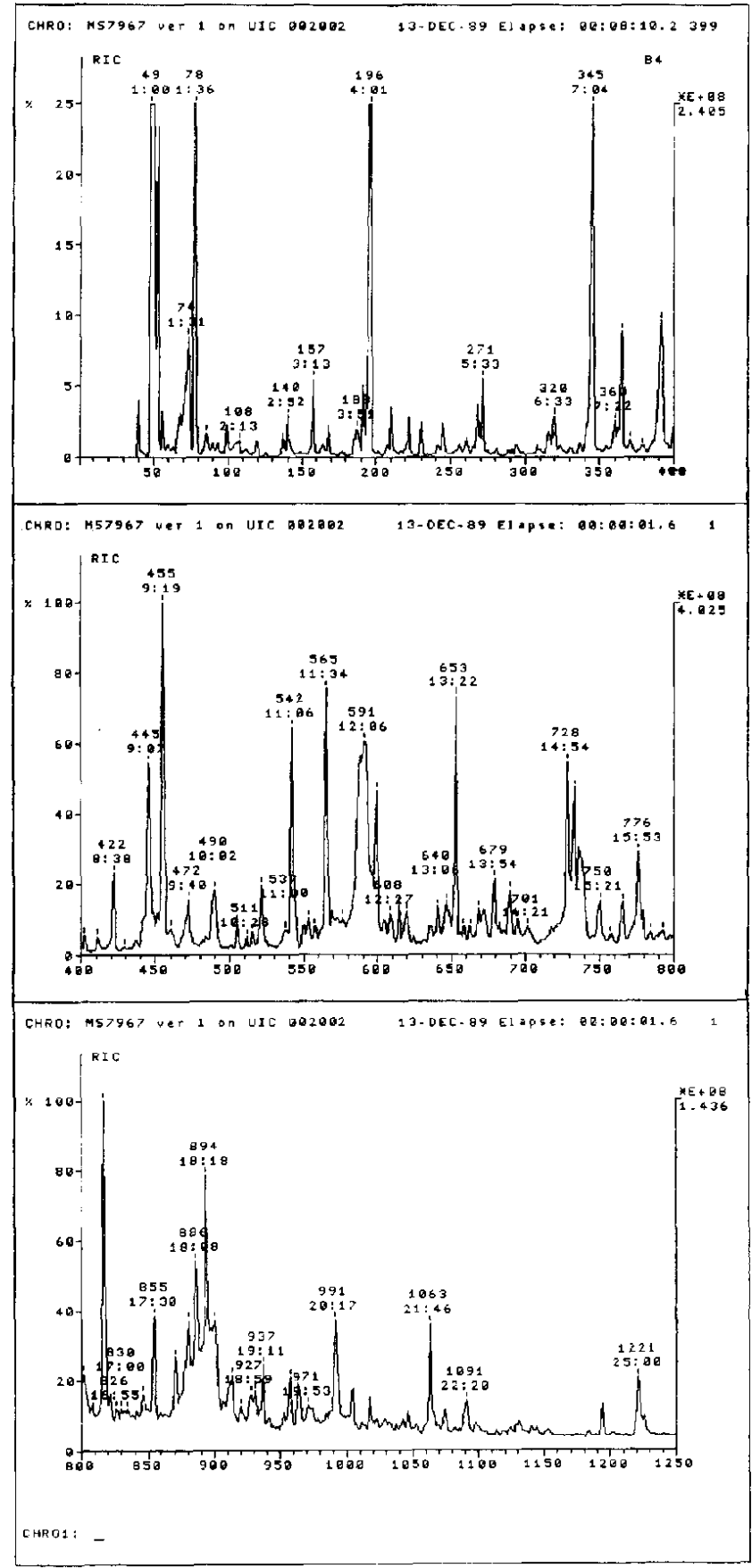

Fig. 1. Reconstructed ion current chromatogram as a function of mass spectrum numbers of pyrolysis products formed after impregnation with $\mathrm{NaCl}$ (experiment 9). 


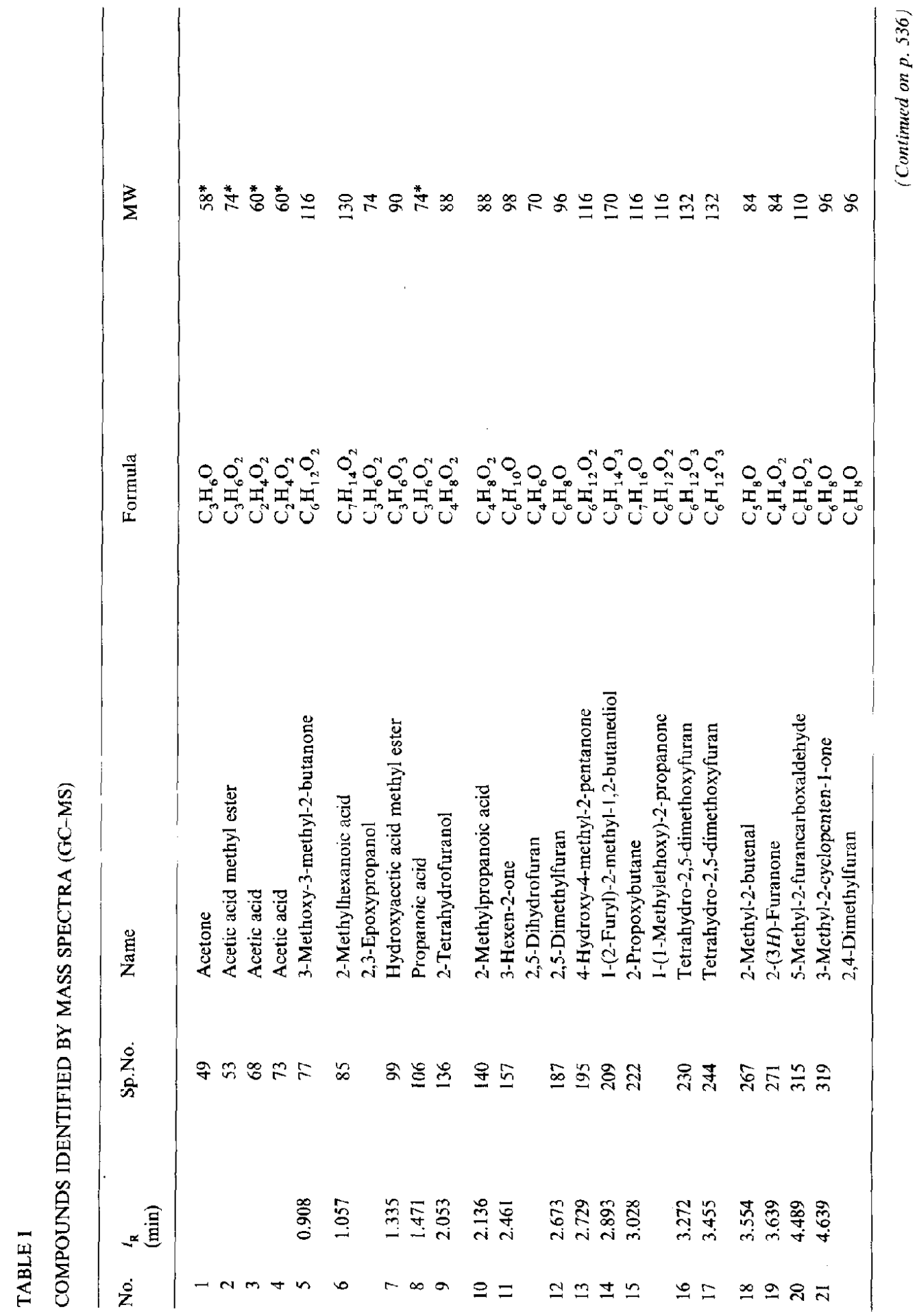




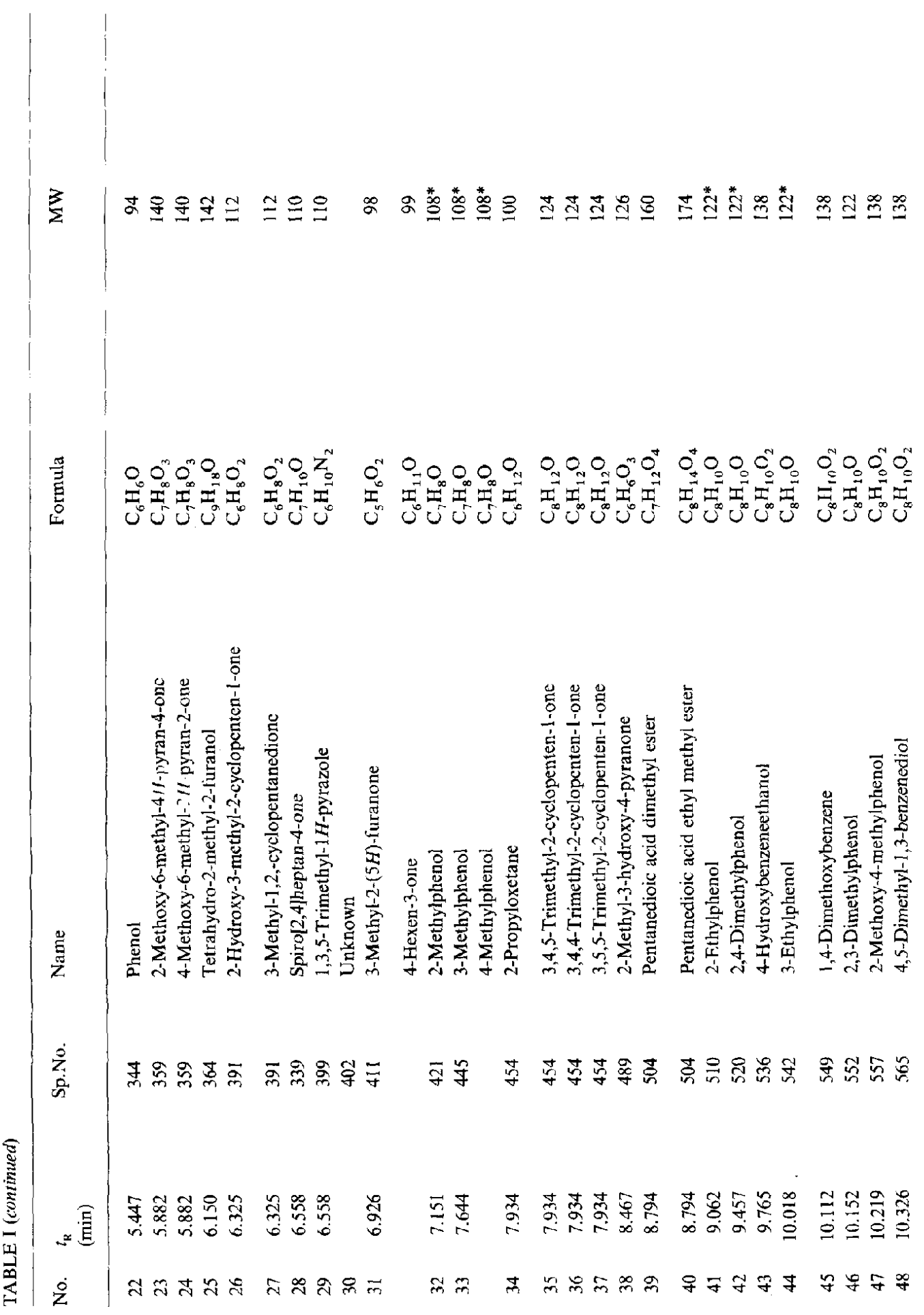




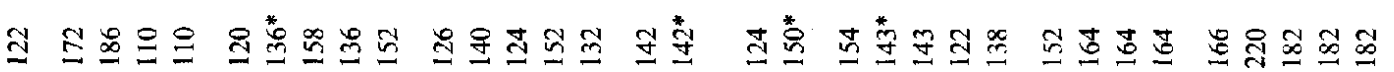

$\begin{array}{llll} & \\ 0\end{array}$

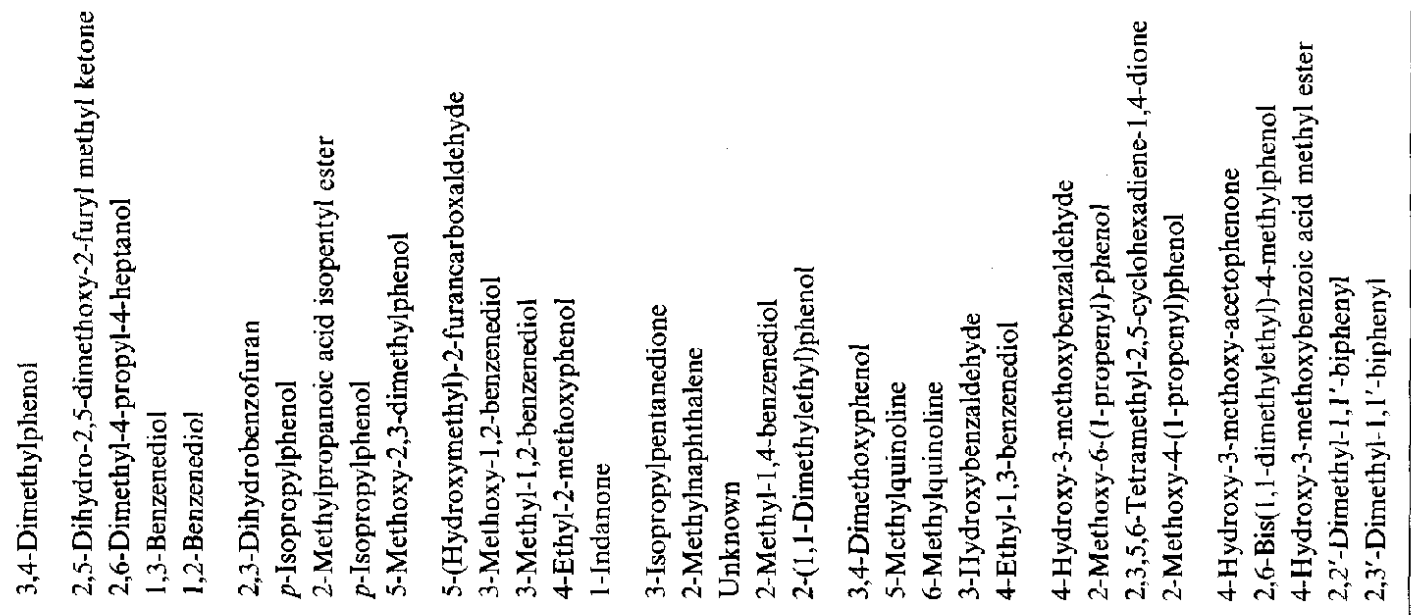

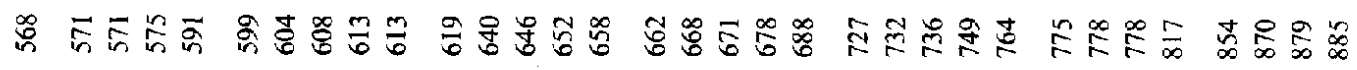

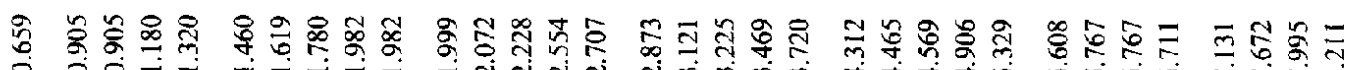

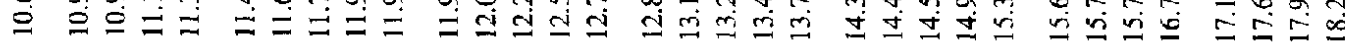

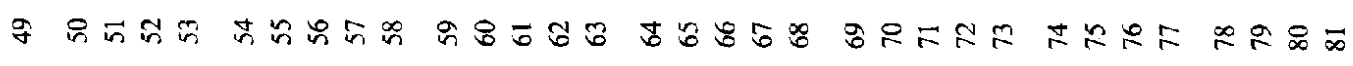




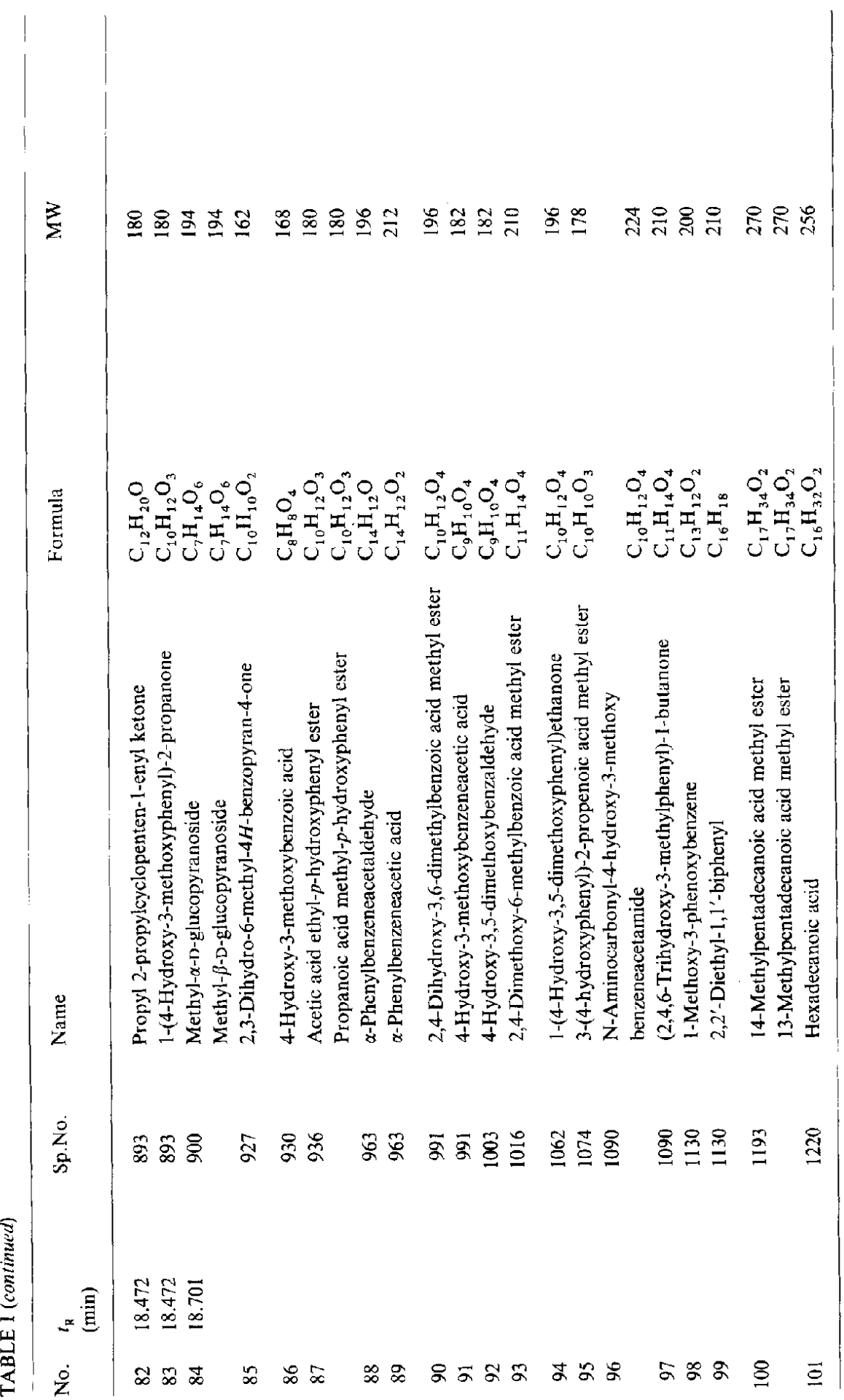




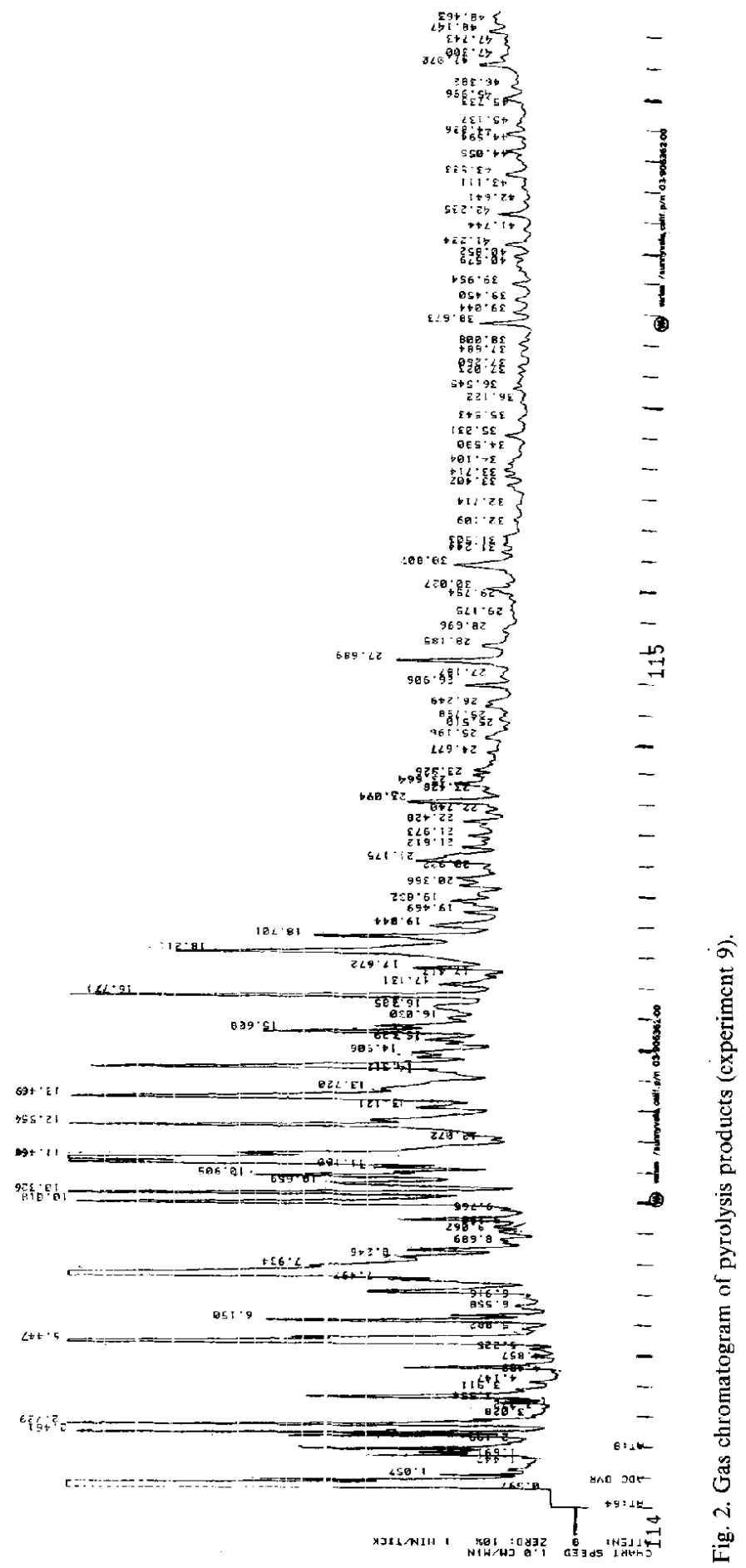




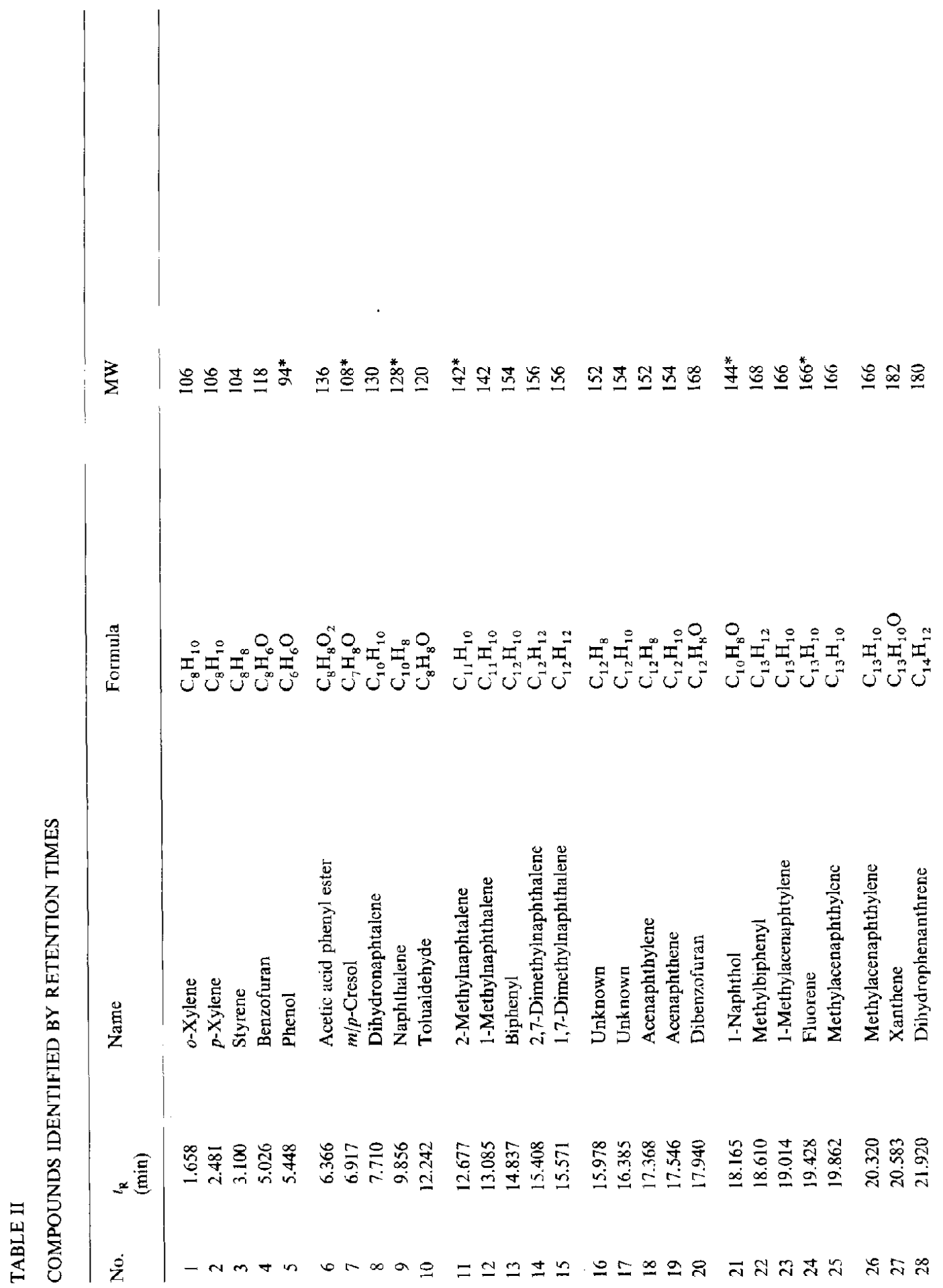




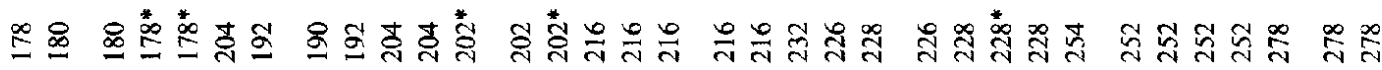

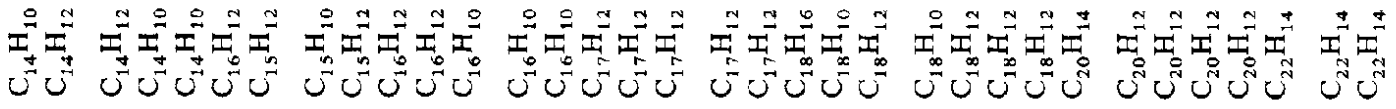
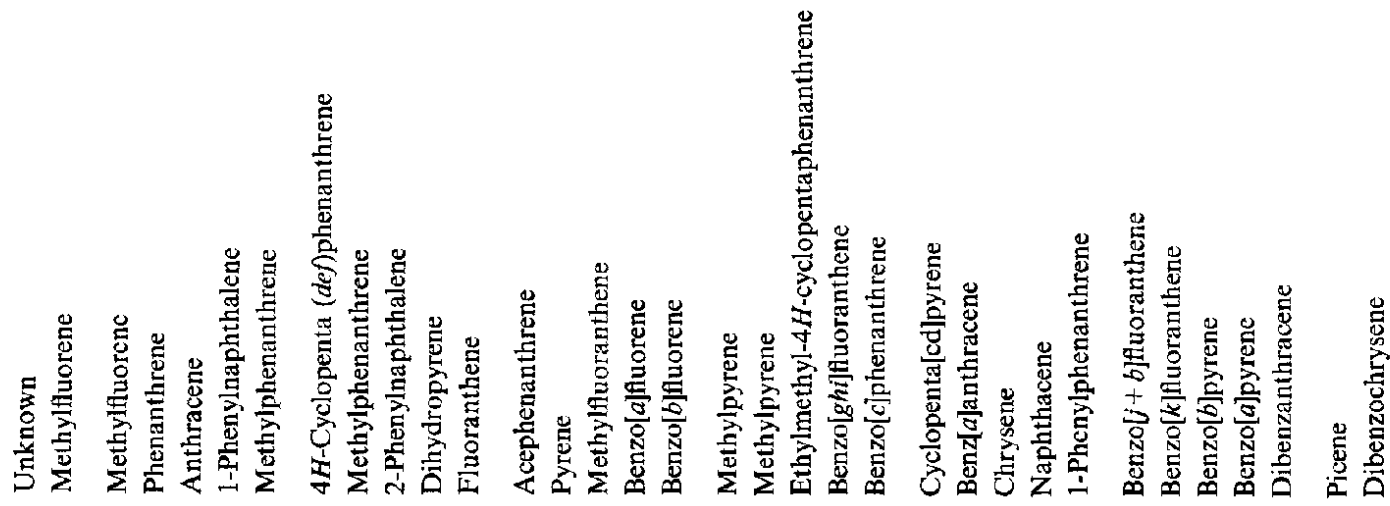

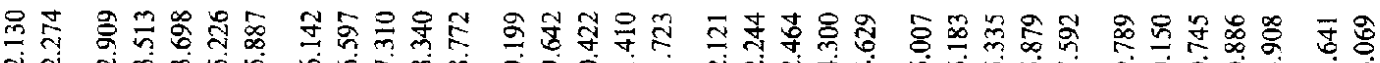

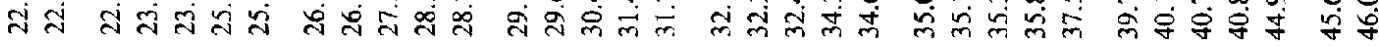

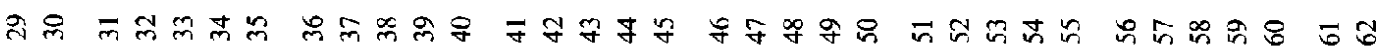




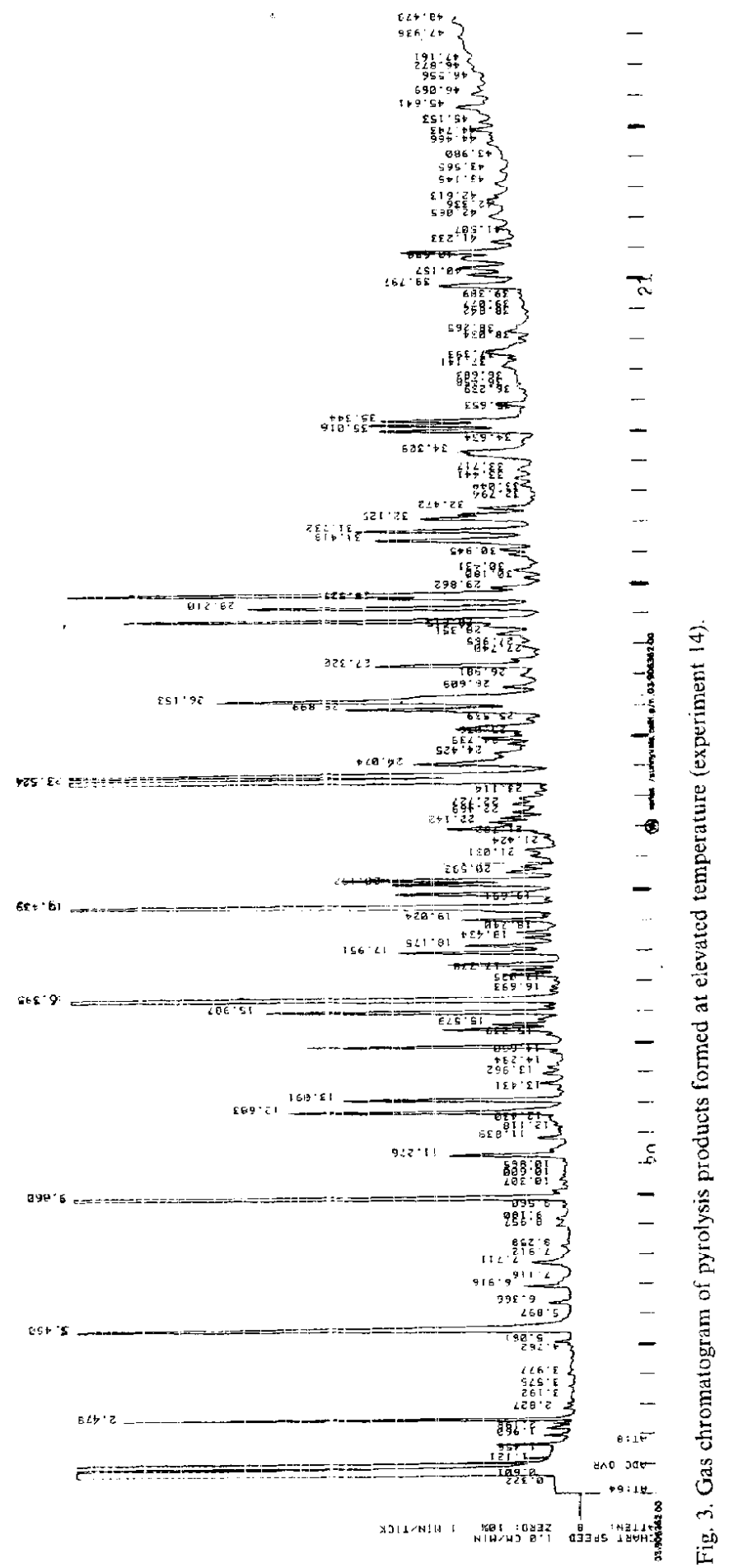


In general, the product composition of tars from rice husks is in good agreement with the composition of coal tar as described by Novotny et al. [8], the main products being hydroxyaromatics and PAHs. However, only a small number of nitrogen-containing compounds were detected.

A striking mass spectrum is scan No. 900 (57-60-137-73-121). A probable fit is methyl- $\alpha$-D-glucopyranoside or its $\beta$-isomer $\left(\mathrm{C}_{7} \mathrm{H}_{14} \mathrm{O}_{6}\right)$. This seems to be the first time that a sugar-type compound has been identified.

The interpretation of some mass spectra is not unambiguous. Some examples are: MS scan No. 222 (strongest peaks 43-86-116-42-73), 2-propoxybutane or 1-(1-methylethoxy)-2-propanone; MS scan No. 319 (96-67-81-53-95), 3-methyl-2-cyclopenten-1-one or 2,4-dimethylfuran; MS scan No. 445 (108-107-77-7179 ); $m$ - or $p$-cresol or (most probably) a mixture.

The retention indices of about 20 of the compounds mentioned in Table I were retrieved in the Sadtler Retention Index Library [6]. Since this library contains only values for $2^{\circ} \mathrm{C}$ and $8^{\circ} \mathrm{C} /$ min temperature increase the mean of these two values was used as a first approximation. In Fig. 4 these calculated R.I. values are plotted against the neat retention times of the independent gas chromatogram, for twelve compounds listed in Table I. In general the relationship is very good, but some very striking results were obtained. Compound 9 (MS scan 136) was

TABLE III

QUANTITATIVE ANALYSIS OF TAR SAMPLES FROM PYROLYSIS OF RICE HUSKS

\begin{tabular}{llllll}
\hline Exp. No. & $\begin{array}{l}\text { Total mass } \\
\text { trapped } \\
(\mathrm{g})\end{array}$ & $\begin{array}{l}\text { Tar } \\
(\mathrm{mg})\end{array}$ & $\begin{array}{l}\text { Hydroxyaromatics } \\
(\mathrm{mg})\end{array}$ & $\begin{array}{l}\text { Polyaromatics } \\
(\mathrm{mg})\end{array}$ & $\begin{array}{l}\text { Benz[a]pyrene } \\
(\mathrm{mg})\end{array}$ \\
\hline 1 & 1.20 & 178 & 68 & 15 & 0.23 \\
2 & 0.84 & 116 & 49 & 9 & 0.12 \\
3 & 0.96 & 188 & 87 & 13 & 0.22 \\
4 & 1.14 & 89 & 42 & 6 & 0.09 \\
5 & 1.20 & 150 & 67 & 12 & 0.21 \\
6 & 0.60 & 157 & 70 & 10 & 0.33 \\
7 & 0.72 & 247 & 78 & 15 & 0.38 \\
8 & 1.08 & 161 & 78 & 11 & 0.16 \\
9 & 1.08 & 252 & 121 & 21 & 0.21 \\
10 & 0.66 & 149 & 83 & 10 & 0.18 \\
11 & 0.36 & 73 & 28 & 8 & 0.15 \\
12 & 0.42 & 111 & 40 & 8 & 0.13 \\
13 & 0.10 & 31 & 4 & 13 & 0.32 \\
14 & 0.12 & 32 & 6 & 14 & 0.24 \\
15 & 0.06 & 50 & 13 & 15 & 0.37 \\
16 & 0.04 & 56 & 26 & 11 & 0.12 \\
\hline
\end{tabular}




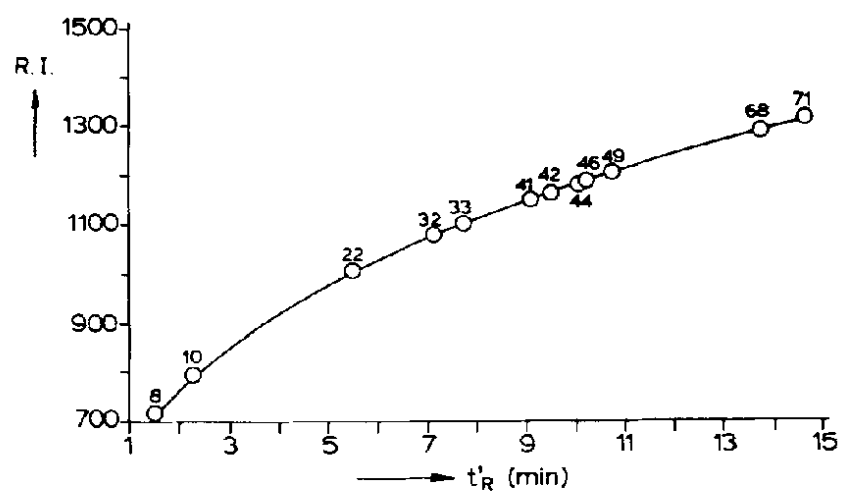

Fig. 4. Litcrature reference values of R.I. plotted as function of neat retention times (experiment 9 , gas chromatogram of Fig. 2). The numbers refer to the compound numbers listed in Table I.

originally interpreted as 3-tetrahydrofuranol, reference index 835.40 , experimental value $c a$. 785. A probable explanation is that this compound is 2 tetrahydrofuranol. For this compound no reference index is available but internal hydrogen bonding might very well lower the index by ca. 50 R.I. units. Compounds 46 and 49 (MS scans 552 and 568) were originally interpreted as 2,5dimethylphenol and 3,5-dimethylphenol, reference indices 1149.59 and 1169.05 , experimental values $c a .1175$ and 1190 . After reconsideration of the mass spectra, the compounds 2,3-dimethylphenol and 3,4-dimethylphenol, retention indices 1177.58 and 1193.38 , appeared a much more probable fit.

These results indicate that the use of retention indices can yield essential additional information to GC-MS interpretation, provided that a sufficiently comprehensive and reliable reference collection is available.

Qualitative analysis of tars and corresponding mixtures is often based on chemical class separation prior to the analysis. Parees and Kamzelski [9] have shown that the analysis of coal-derived liquids can be performed in one run without previous separation by using GC-MS with a fused-silica SE 54 GC column. This work supports this approach despite the fact that the interpretation of some mass spectra is slightly hindered by peak overlap.

From Table III it can be concluded that production of tar is reduced by $c a$. $50 \%$ when rice husks are impregnated with potassium carbonate, by $c a .90 \%$ on thermal cracking at higher temperatures and by $c a .97 \%$ on catalytic cracking. Formation of hydroxyaromatics is hardly influenced by the addition of catalysts, but thermal cracking reduces the amounts by $80-95 \%$, especially at higher temperatures (experiments 13-15). On catalytic cracking a reduction of $70 \%$ is obtained. The influence on polyaromatics is somewhat smaller: addition of potassium carbonate or calcium carbonate and thermal cracking yield ca. $50 \%$ reduction and catalytic cracking $c a .30 \%$. Finally, benz $[a]$ pyrene is reduced from $0.23 \mathrm{mg}$ to $0.12 \mathrm{mg}(\mathrm{ca} .50 \%$ ) on catalytic cracking. In experiment 16 the total 
amount of material trapped was somewhat lower than the amount of tar determined: this is probably caused by the inaccuracy inherent.in the weighing procedure.

\section{REFERENCES}

1 A. Kaupp and R. J. Goss, Small Scale Gas Producer-Engine Systems, F. Vieweg, Wiesbaden, 1984.

2 O. Beaumont and Y. Schwob, Ind. Eng. Chem. Chem. Process Des. Dev., 23 (1984) 637.

3 E. G. Baker, L. K. Mudge and D. H. Mitchell, Ind. Eng. Chem. Chem. Process Des. Dev., 23 (1984) 727.

4 Eight Peak Index of Mass Spectra, The Mass Spectrometry Data Centre, The Royal Society of Chemistry, Nottingham, 1983.

5 H. van den Dool and P. D. Kratz, J. Chromalogr., 11 (1963) 463.

6 The Sadtler Standard Gas Chromatography Retention Index Library, Sadtler Research Laboratories, Philadelphia, PA, 1986.

7 M. L. Lee, D. L. Vassilaros, C. M. White and M. Novotny, Anal. Chem., 51 (1979) 768.

8 M. Novotny, J. W. Strand, S. L. Smith, D. Wiesler and F. J. Schwende, Fuel, 60 (1981) 213.

9 D. M. Parees and A. Z. Kamzelski, J. Chromatogr. Sci., 20 (1982) 441. 